\title{
Numerical analysis of the impact of natural ventilation on the Indoor Air Quality and Thermal Comfort in a classroom
}

\author{
George-Mădălin Chitaru ${ }^{1}$, Andrei Istrate $^{1}$, and Tiberiu Catalina ${ }^{1, *}$ \\ ${ }^{1}$ Technical University of Civil Engineering of Bucharest, Faculty of Building Services, \\ 66 Pache Protopopescu Bvd., District 2, 021414, Bucharest, Romania
}

\begin{abstract}
Indoor air quality (IAQ) inside educational institutions is an important topic in the field of building and health research. School absenteeism and educational performance have been linked to poor air quality inside classrooms. A numerical simulation software has been used to test 5 different scenarios of natural ventilation during summer and winter. $\mathrm{CO}_{2}$ levels, air relative humidity, operative temperature and PMV were used as indoor air quality and thermal comfort indicators. Results have shown high $\mathrm{CO}_{2}$ and humidity levels when all windows are closed, and a variable improvement when different natural ventilations strategies are employed. A detailed procedure for the numerical simulation has been presented.
\end{abstract}

\section{INTRODUCTION}

Since the energy crises of the 1970s, many of the leading industrial countries have been focusing on improving the energy efficiency strategies to reduce the overall energy consumption. While the countries that were rich in oil have benefited from this crisis period, others were shocked by the petroleum shortages and their governments have been forced to take drastic measures to reduce the consumption of the available resources [1]. For the civil engineering domain, these measures have represented the start of most of the indoor air quality related problems such as indoor air pollution or ,sick building syndrome", as the building owners were forced to reduce the energy costs by using highly insulated building envelopes and by reducing the functionality of the heating, ventilation and air conditioning (HVAC) systems [2].

For several years, all the attention was driven towards the energy efficiency of the buildings, mostly due to the general idea that the indoor environment was protected from the pollution outside. In the 1980s, after the release of several studies by different institutions all around the world, there was clear evidence of poor air quality in indoor environments. And soon after it was recognized as a serious threat for the occupants well-being [3].

Since then, there has been a continuous struggle between the concept of energy efficient buildings and the concept of healthy indoor environment, mostly because the advantages of one meant a compromise for the other (for example, tightly constructed new buildings have lower energy requirements, but usually present higher concentrations of indoor air pollutants if a proper ventilation system is not installed).

During the last decades, the number of studies regarding indoor air quality (IAQ) has increased significantly and there are now national and international organizations that work together to implement worldwide regulations and standards with the goal to improve the overall indoor experience of the occupants by providing a healthy and comfortable environment [4]. Even though productivity in school is an important objective for any society, most of these studies have been performed for residential, industrial and office buildings, with only a small percentage being targeted at educational buildings [5].

In Europe, during school days, there are on average 68 million occupants (both students and teachers) that are affected by the quality of the air inside the educational institutions [6]. Therefore, it is of utmost importance to ensure a healthy school environment in order to promote effective learning. It's also important to keep the occupants (children) safe from any avoidable health risk factors that could cause asthma, allergic reactions, heart diseases, pulmonary diseases, headaches and other health issues.

During the past 20 years there have been a few studies linking school absenteeism with poor air quality $[7,8]$ and many other studies that have shown the influence of high pollutant concentrations on the people inside [9]. Moreover, the children are more vulnerable to environmental pollutants because they tend to have higher respiratory rates that directly increase the dose of pollutants that get into the lungs. Considering that their young bodies may not be able to deal with some of the toxic chemicals found in the air, children are also more prone to develop health issues that may have long term effects. [10,11].

There are many variables that have to be taken into consideration when designing a ventilation scenario for a classroom full of students: the number of occupants, the age and the activity level of the occupants, the daily occupational schedule, the geometry of the

* Corresponding author: tiberiu.catalina@gmail.com 
building/classroom, the structure of the building, the age of the building, the outdoor climate, the level of maintenance, the current state of the HVAC system, etc. All these variables make it very difficult to propose a general guideline on how to achieve a healthy indoor environment without doing some in-situ measurements to verify the IAQ level. This is where numerical simulation software could play an important role in the development of ventilation strategies for schools.

All the variables mentioned earlier can be easily changed within a simulation program and, if the model is set-up correctly, the simulation results could help a professional HVAC engineer determine if a certain ventilation strategy is viable or not. Of course, a computer program cannot offer an exact image of the real situation, therefore experimental validation is also necessary. However, the extra time gained by using the software to predict the proper ventilation method is significant.

The current paper focuses on developing a numerical simulation procedure that can be used to evaluate the efficiency of a natural ventilation strategy by monitoring the carbon dioxide $\left(\mathrm{CO}_{2}\right)$ evolution inside a high school classroom full of students. For each of the ventilation scenarios the thermal comfort, air humidity and energy consumption were taken into consideration by extracting the variation of the operative temperature $\left(\mathrm{T}_{\mathrm{OP}}\right)$, relative indoor air humidity (RH), PMV, PPD, and heat load. The inclusion of these parameters allows to achieve a holistic view of the efficiency of the ventilation method which, correlated with the costs, can offer important information regarding the viability of the solution before implementing into practice.

The software used for running the simulations was Design Builder Version 5, which relies on the Energy Plus code. The virtual model of the classroom has been realized with the same software using the architectural plans and the orientation of the real building. The results have been extracted using the "Design Builder Results Viewer" extension and the post processing of the data has been realized with Microsoft Excel.

\section{CASE STUDY \& METHODOLOGY}

\subsection{Description of the real classroom}

The classroom used for this study is located on the first floor of „Mihai Viteazul” high school, in Bucharest. As presented in Fig. 1, the room has a length (L) of $9 \mathrm{~m}$, a width (W) of $6.8 \mathrm{~m}$ and a height $(\mathrm{H})$ of $4.9 \mathrm{~m}$ resulting in a total usable ground surface area $\left(\mathrm{S}_{\mathrm{t}}\right)$ of $61.2 \mathrm{~m}^{2}$ and an interior volume $\left(\mathrm{V}_{\mathrm{i}}\right)$ of $300 \mathrm{~m}^{3}$. During the school year when this article was written, there were maximum 25 students and 1 teacher present in the classroom. The weekly schedule was Monday to Friday from 8:00 AM to 14:00 PM. The classroom was empty the rest of the time. As seen in Fig. 1, the student's desks are distributed in 3 columns and 6 rows, with a special teacher's desk in front of the classroom. The total number of seats was higher than the number of occupants at the time the article was written, therefore we could expect differences in air quality and thermal comfort from one year to another, depending on the variation in the number of children. This shows again an advantage for the numerical simulation approach, because the number of students can be easily changed to see how a higher or a lower number of occupants can affect the indoor parameters. The local heating system consists of 3 heating radiators with a specific power $\left(\mathrm{P}_{\mathrm{rad}}\right)$ of $1800 \mathrm{~W} /$ unit. This means that the total installed heating power $\left(\mathrm{P}_{\text {tot }}\right)$ is $5.4 \mathrm{~kW}$. The lighting installation is made up of 9 LED lamps mounted on the ceiling and symmetrically divided over the entire surface of the ceiling. Each lamp provides $43 \mathrm{~W}$ electrical power, 4,400 lumens with a colour temperature of 4000 Kelvin and a colour rendering index CRI80. The luminous flux in the working plan $(0.7 \mathrm{~m}$ height $)$ is of 550 lux.

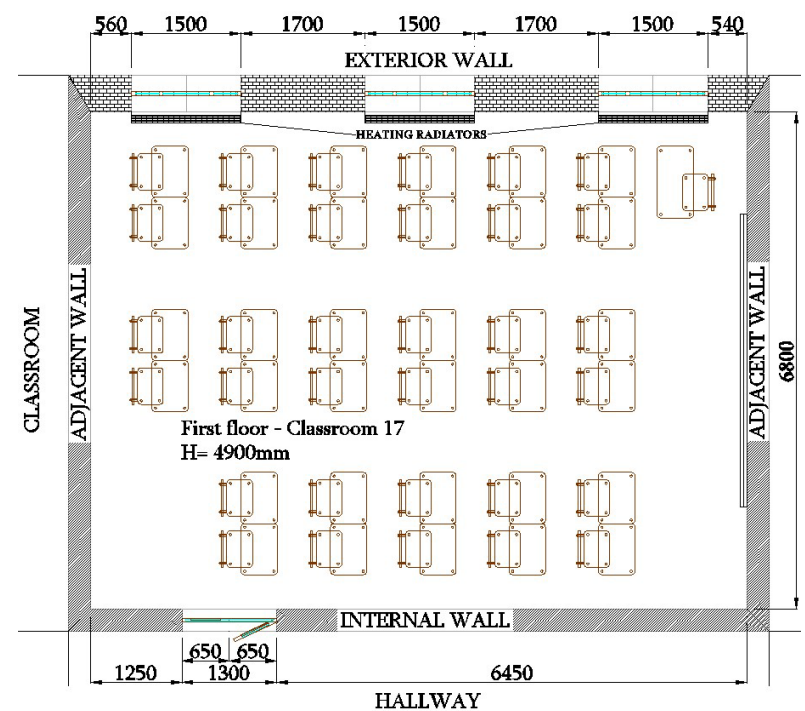

Fig. 1. Layout and dimensions of the real classroom

As presented in Table 1, the exterior walls of the building are made of a $90 \mathrm{~cm}$ full brick layer with cement plaster finish on both sides. The interior or adjacent walls are made of a $35 \mathrm{~cm}$ layer of the same full brick type, with gypsum plaster on both sides. The adjacent floor and ceiling are made of concrete slab with gypsum plaster finish on the ceiling side and a parquet wooden finish on the floor side. As seen in Fig. 2, the classroom has 3 double glazed windows, with an arched top side, presenting the following dimensions:

- Rectangular zone: length (L) $1.5 \mathrm{~m}$, height $(\mathrm{H}) 2 \mathrm{~m}$;

- Semi-circle shaped zone: length (L) $1.5 \mathrm{~m}$, radius (r) $0.75 \mathrm{~m}$.

The windows have only one opening area in the rectangle shaped zone and this area represents about one third (1/3) of the full rectangular zone. The opening presents the following dimensions: length (L) $0.5 \mathrm{~m}$, height $(\mathrm{H}) 2 \mathrm{~m}$.

The classroom also has two plywood doors, each one having a ventilation grille installed in the lower half with the purpose of improving the ventilation rate when the windows are opened. The doors have a total length (L) of $1.3 \mathrm{~m}$ and a height $(\mathrm{H})$ of $2.5 \mathrm{~m}$ with the grilles having a length $(\mathrm{L})$ of $0.45 \mathrm{~m}$ and a height $(\mathrm{H})$ of $0.3 \mathrm{~m}$. Above 
the doors there is also a fixed window area with a length (L) of $1.3 \mathrm{~m}$ and a height $(\mathrm{H})$ of $0.5 \mathrm{~m}$.

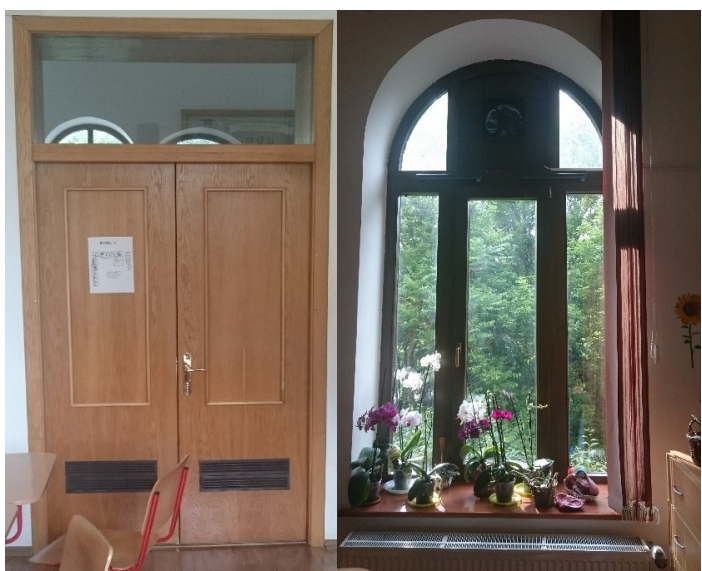

Fig. 2. Geometry of the classroom door and window

To ensure a good correspondence between reality and numerical simulation, the virtual model must be carefully set-up and thoroughly verified before assuming that the results are worth taking into consideration. In order to avoid human errors a specific flow of the process has been realized before starting the design of the virtual model.

\subsection{Defining the virtual model}

The software used to create the $3 \mathrm{D}$ virtual model of the classroom and to run the numerical simulations was Design Builder V 5.0.2. Design builder is a multi-zone simulation toolbox that offers CAD/BIM model importing, intuitive and easy to use $3 \mathrm{D}$ design tools, EnergyPlus algorithm for HVAC, airflow, daylight, energy efficiency and costs simulations, weather file import and advanced 3D visualization system for sun patterns and shadings and a CFD module for an in-depth analysis of certain areas of a building.

Firstly, to create the 3D model, the 2D CAD plan of the classroom has been imported into the program and the classroom block was created. The 4 walls have been set to their corresponding type (exterior, internal or adjacent) and their structure has been defined using materials with properties as close as possible to the real case. The physical properties of the layers used for each of the structural elements are presented in Table 1.

The adjacent floor, adjacent roof, and two of the adjacent walls have been changed to adiabatic elements because it was considered that the temperature in the neighbouring classrooms is not much different from the test classroom. However, the program still considers the thermal mass of the structural elements. Therefore, it is still very important to define the construction type correctly even for adiabatic cases.

To take into consideration the pressure difference and to correctly predict the airflow through the door grilles, a portion of the hallway was also created and the $3 \mathrm{rd}$ adjacent wall was set as an internal partition between the classroom and the hallway.

After defining the structural elements, the windows and doors have been added to the model. A double-glazed window model has been chosen from the software's own library, since the definition of a custom type of window implies a lot of calculations which were considered unnecessary for the purpose of this study. The window presents the following characteristics: Low-E $3 \mathrm{~mm}$ exterior glass layer, a $13 \mathrm{~mm}$ Argon layer in the middle and a clear $3 \mathrm{~mm}$ interior glass layer with a total solar transmittance $(\tau)$ of 0.595 and a conductivity $(\mathrm{u})$ of 1.5 $\left[\mathrm{W} / \mathrm{m}^{2} \cdot \mathrm{K}\right]$.

The doors, however, have been modelled as a single layer of $4 \mathrm{~cm}$ of Plywood which resulted in an average conductivity (u) of $2.3\left[\mathrm{~W} / \mathrm{m}^{2} \cdot \mathrm{K}\right]$.

The hallway has been modelled as a closed zone with three exterior walls, an adiabatic floor, an adiabatic ceiling, and with an interior wall adjacent to the classroom. The interior dimensions of the hallway section are: width (W) $3 \mathrm{~m}$, length (L) $7.55 \mathrm{~m}$ and height (H) $4.9 \mathrm{~m}$. On the smaller exterior walls, two windows of $3 \mathrm{~m} \times 2 \mathrm{~m}(\mathrm{~L} \times \mathrm{H})$ have been added to account for some of the infiltrations that are present on the hallway. This was only a rough approximation of the real phenomena. But considering that there was no interest in analysing the thermal comfort or the air quality on the hallway, a more accurate simulation was not necessary.

Table 1. Properties of the structural elements

\begin{tabular}{|c|c|c|c|c|c|}
\hline \multirow{2}{*}{ Exterior Wall } & $\delta$ & $\lambda$ & $c_{p}$ & $\rho$ & $\mathrm{U}$ \\
\hline & {$[\mathrm{m}]$} & {$[\mathrm{w} / \mathrm{m} \cdot \mathrm{K}]$} & {$[\mathrm{J} / \mathrm{kg} \cdot \mathrm{K}]$} & {$\left[\mathrm{kg} / \mathrm{m}^{3}\right]$} & {$\left[\mathrm{W} / \mathrm{m}^{2} \cdot \mathrm{K}\right]$} \\
\hline Cement plaster & 0.01 & 0.72 & 840 & 1760 & \multirow{3}{*}{0.682} \\
\hline Full Brick & 0.9 & 0.72 & 840 & 1920 & \\
\hline $\begin{array}{c}\text { Gypsum } \\
\text { Plaster }\end{array}$ & 0.013 & 0.4 & 1000 & 1000 & \\
\hline \multirow{2}{*}{$\begin{array}{c}\text { Internal/ } \\
\text { Adjacent Wall }\end{array}$} & $\delta$ & $\lambda$ & $c$ & 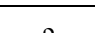 & $U$ \\
\hline & [m] & {$[\mathrm{w} / \mathrm{m} \cdot \mathrm{K}]$} & {$[\mathrm{J} / \mathrm{kg} \cdot \mathrm{K}]$} & {$\left[\mathrm{kg} / \mathrm{m}^{3}\right]$} & {$\left[\mathrm{W} / \mathrm{m}^{2} \cdot \mathrm{K}\right]$} \\
\hline $\begin{array}{c}\text { Gypsum } \\
\text { Plaster }\end{array}$ & 0.013 & 0.4 & 1000 & 1000 & \multirow{3}{*}{1.423} \\
\hline Full Brick & 0.35 & 0.72 & 840 & 1920 & \\
\hline $\begin{array}{l}\text { Gypsum } \\
\text { Plaster } \\
\end{array}$ & 0.013 & 0.4 & 1000 & 1000 & \\
\hline \multirow{2}{*}{$\begin{array}{l}\text { Adjacent } \\
\text { Floor/Roof }\end{array}$} & $\delta$ & $\lambda$ & $\mathrm{c}_{\mathrm{p}}$ & $\rho$ & $\mathrm{U}$ \\
\hline & {$[\mathrm{m}]$} & {$[\mathrm{w} / \mathrm{m} \cdot \mathrm{K}]$} & {$[\mathrm{J} / \mathrm{kg} \cdot \mathrm{K}]$} & {$\left[\mathrm{kg} / \mathrm{m}^{3}\right]$} & {$\left[\mathrm{W} / \mathrm{m}^{2} \cdot \mathrm{K}\right]$} \\
\hline Plywood floor & 0.01 & 0.15 & 2500 & 560 & \multirow{3}{*}{2.27} \\
\hline Concrete & 0.1 & 1.4 & 840 & 2100 & \\
\hline $\begin{array}{l}\text { Gypsum } \\
\text { Plaster }\end{array}$ & 0.013 & 0.4 & 1000 & 1000 & \\
\hline
\end{tabular}

After creating the enclosed environment, the next step was to define the different scenarios for: occupancy, HVAC components and natural ventilation. 


\subsection{Occupancy Scenario}

As specified in the description of the classroom (subchapter 2.1) during the school year this article was written, the total number of occupants was of maximum 25 students plus 1 teacher. Therefore, an occupation density $\left(\rho_{\text {occ }}\right)$ of 0.42 people $/ \mathrm{m}^{2}$ was considered for the simulations. This resulted in a nominal number of occupants $\left(\mathrm{N}_{\mathrm{occ}}\right)$ of 26 people. Even though the classroom can accommodate up to 34 students, we decided to use the exact number of students present for that school year because some of the simulation results would then be compared to experimental data gathered during the same period.

The weekly occupancy schedule was set just as described in subchapter 2.1. Starting from Monday to Friday, with the start of the school day at 8:00AM and end of the school day at 14:00PM. The weekends were considered „no school” days, and winter and summer holidays were also considered. However, since we were not interested in annual results the influence of the holidays was not of great importance.

To also take into consideration the dynamic factor of the occupancy (children leaving classroom during breaks, teachers present only during class) a variable daily schedule was used. This schedule considered a coefficient of 0.5 (half occupancy) for the classroom occupancy during class breaks. The schedule used for the numerical simulation can be seen in Table 2 .

Table 2. Weekly Occupancy Schedule

\begin{tabular}{|c|c|c|}
\hline Time & Monday -> Friday & Saturday $->$ Sunday \\
\hline $7: 50$ & Children entering class & \multirow{15}{*}{$\begin{array}{c}\text { No persons inside the } \\
\text { classroom }\end{array}$} \\
\hline 8:00 & 1 st class, 26 persons & \\
\hline $8: 50$ & 1 st break, 13 persons & \\
\hline 9:00 & 2nd class, 26 persons & \\
\hline 9:50 & 2nd break, 13 persons & \\
\hline $10: 00$ & 3rd class, 26 persons & \\
\hline $10: 50$ & 3rd break, 13 persons & \\
\hline $11: 00$ & 4th class, 26 persons & \\
\hline $11: 50$ & 4th break, 13 persons & \\
\hline $12: 00$ & 5th class, 26 persons & \\
\hline $12: 50$ & 5 th break, 13 persons & \\
\hline 13:00 & 6th class, 26 persons & \\
\hline $13: 50$ & 6th break, 13 persons & \\
\hline $14: 00$ & Children leaving class & \\
\hline $\begin{array}{c}14: 00 \text { to } \\
7: 50\end{array}$ & No persons inside the classroom. & \\
\hline
\end{tabular}

For the hallway, the occupancy settings were left at the default values of the "Universities and Colleges Circulation area, corridors and stairways" activity template. An occupancy schedule has also been defined, with full occupancy factor $\left(\mathrm{N}_{\mathrm{occ}}=2.41\right.$ people $)$ during the breaks and no occupancy during the classes.

After defining the occupancy schedule, the metabolic template was introduced. From the available templates the „Light office work/Standing/Walking” one was chosen, as it was considered the most suitable for a classroom full of students, which usually move more during the day compared to a typical adult at an office. The selected template introduces a nominal metabolic rate per person (Met) of $123 \mathrm{~W} /$ pers, but this value was multiplied by a metabolic factor $\left(\mathrm{C}_{\mathrm{met}}\right)$ of 0.83 since it is considered that adolescents produce less heat than adults due to their improved health condition and due to the reduced body size. The metabolic factor was chosen as an average between the values recommended by Schofield [12] and the ones recommended by the World Health Organization (WHO) [13], for both genders. These values have been used in several studies and they have proven to properly predict the basal metabolic rate (BMR) in adolescents with ages between 10 and 18 years old [14].

For the $\mathrm{CO}_{2}$ generation rate, the software suggests a recommended value depending on the activity template that was chosen. This value can also be set manually. However, one of the objectives of the study is to see how well a numerical simulation program can estimate the indoor $\mathrm{CO}_{2}$ production without much need for additional experimental data. Therefore, the $\mathrm{CO}_{2}$ generation rate $\left(\mathrm{qCO}_{2}\right)$ was left at the default value of $3.82 \times 10^{-8}$ $\left[\mathrm{m}^{3} / \mathrm{s} \cdot \mathrm{W}\right]$, which has been verified with data from other sources [15] and it was found to be in the recommended range, with a total $\mathrm{CO}_{2}$ emission:

$$
E_{\mathrm{CO} 2}=q_{\mathrm{CO} 2} \times \mathrm{Met} \times 1000=0.0039[\mathrm{~L} / \mathrm{s} \cdot \mathrm{pers}]
$$

The recommended range specified by Persily and de Jonge [15] is $\mathrm{E}_{\mathrm{CO} 2}=0.0036 \mathrm{~L} / \mathrm{s} \cdot$ pers for adolescent females and $\mathrm{E}_{\mathrm{CO} 2}=0.0045 \mathrm{~L} / \mathrm{s} \cdot$ pers for adolescent males. It is worth noting that the input value for the $\mathrm{CO}_{2}$ generation rate $\left(\mathrm{q}_{\mathrm{CO} 2}\right)$ depends on the metabolic level of the people. Therefore, the program will properly calculate the $\mathrm{CO}_{2}$ concentration even when the no. of occupants or the activity within a zone is changing.

For the calculation of the thermal comfort indices (PMV, PPD) a clothing level of 1 Clo was chosen for winter and a clothing level of 0.5 Clo was chosen for summer.

The indoor comfort outputs are influenced by both temperature and humidity, therefore the internal algorithm, based on a polynomial function, was used to calculate the latent and sensible heat gains from the occupants.

\subsection{HVAC Scenario}

As mentioned in Subchapter 2.1, the HVAC system consists of only fixed heating radiators that can offer a total heating power $\left(\mathrm{P}_{\mathrm{tot}}\right)$ of around $5400 \mathrm{~W}$. In order to evaluate thermal comfort, the program offers multiple models to calculate Room Air Distribution. However, the full mixed model, used in our case, considers the air temperature as being uniform throughout the zone [16]. 
For a more detailed analysis of the comfort inside the classroom a CFD simulation might be more adequate. A schedule has also been used for the heating system, since this is an important factor that influences the indoor thermal comfort. The system was considered to run at full capacity from early in the morning (4:00 AM), so that the walls would heat up until the students arrive, until the end of the school program (14:00 PM). During the rest of the day, from 14:00 PM to 04:00 AM, the system was considered running at partial capacity. The same was considered during weekends and holidays. The system is controlled by two temperature values for each zone: a comfort temperature ( $\left.t_{c}\right)$ and a setback temperature $\left(t_{s b k}\right)$. The comfort temperature $\left(t_{c}\right)$ was set to $24{ }^{\circ} \mathrm{C}$ for the classroom and $20{ }^{\circ} \mathrm{C}$ for the hallway. The setback temperature $\left(\mathrm{t}_{\mathrm{sbk}}\right)$ was defined globally at $15^{\circ} \mathrm{C}$. The setback temperature is used to reduce the energy consumption while avoiding indoor condensation and keeping the heating system at a safe temperature (to avoid freezing of the water inside the radiators).

The software also allows the selection of temperature control type between Mean Air Temperature or Operative Temperature. Since most thermostats use the mean air temperature, we decided to also use this type as the control temperature. This means that the actual thermal sensation will not be of $24{ }^{\circ} \mathrm{C}$, but of a lower value corresponding to the operative temperature, as it will be shown later in the results section.

For this study there was no cooling system present in the classroom. Therefore, one objective was to see if the temperature in the classroom can be kept at a reasonable level just by using natural ventilation through open windows.

Table 2. Weekly HVAC Schedule

\begin{tabular}{|c|c|c|c|}
\hline Time & Monday -> Friday & Weekend & Holidays \\
\hline 0:00- $4: 00$ & Set back temperature $15^{\circ} \mathrm{C}$ & Set back & $\begin{array}{c}\text { Set back } \\
\text { temperature } \\
15^{\circ} \mathrm{C}\end{array}$ \\
\cline { 1 - 2 } 4:00- 14:00 & $\begin{array}{c}\text { Comfort temperature } \\
\left(24^{\circ} \mathrm{C} / 20^{\circ} \mathrm{C}\right)\end{array}$ & $\begin{array}{c}\text { temperature } \\
15^{\circ} \mathrm{C}\end{array}$ \\
\cline { 1 - 2 } $14: 00-24: 00$ & Set back temperature $15^{\circ} \mathrm{C}$ & & \\
\hline
\end{tabular}

\subsection{Ventilation Scenario}

The main objective of the study is to test different ventilation methods and then compare and analyse the results to see how each method performs during the two extreme seasons, winter and summer. To accomplish this, a set of four case scenarios has been considered for each season (See Table 3). For these scenarios two ventilation schedules have been used: one that considers the windows opened only during breaks and another that considers the windows opened during the whole time the children are inside (8:00 AM to 14:00 PM). Along with the schedules, two different percentages for the open window area have been used: one that considers only a single window opened to $50 \%$ of the glazed area and another that considers all three windows opened to $50 \%$ of the glazed area.
Even though there are numerous possibilities when using a simulation program like this, the decision to use only the four presented cases has been made based on most probable situations and worst/best case scenarios. This way there was less, but enough, post processing data to verify the accuracy of the software in estimating a reallife situation.

Table 3. Ventilation scenarios for Summer and Winter

\begin{tabular}{|c|c|c|c|}
\hline CASE & SCHEDULE & $\begin{array}{l}\text { OPENED } \\
\text { WINDOWS }\end{array}$ & OPEN AREA \\
\hline Reference & No ventilation. & 0 & 0 \\
\hline Case 1.A & \multirow{2}{*}{$\begin{array}{l}\text { Ventilation only } \\
\text { during breaks (10 } \\
\text { mins between } \\
\text { classes) }\end{array}$} & $\begin{array}{l}3 \text { Windows } \\
(3.6 \mathrm{ACH})\end{array}$ & \multirow{4}{*}{$\begin{array}{l}50 \% \text { per window } \\
\left(0.5 \mathrm{~m}^{2} / \text { window }\right)\end{array}$} \\
\hline Case 1.B & & $\begin{array}{l}1 \text { Window } \\
\text { (1.2 ACH) }\end{array}$ & \\
\hline Case 1.C & \multirow{2}{*}{$\begin{array}{l}\text { Continuous } \\
\text { ventilation from } \\
8: 00 \text { to } 14: 00\end{array}$} & $\begin{array}{l}\text { 1 Window } \\
\text { (1.2 ACH) }\end{array}$ & \\
\hline Case 1.D & & $\begin{array}{l}3 \text { Windows } \\
(3.6 \mathrm{ACH})\end{array}$ & \\
\hline
\end{tabular}

\subsection{Evaluating IAQ}

There have been several studies that linked different aspects of IAQ to the ventilation rate and to the $\mathrm{CO}_{2}$ concentration inside a building [17,18]. Most of the studies are using the $\mathrm{CO}_{2}$ level as an indicator of the indoor air quality level and to know how well an indoor space is ventilated $[9,19,20]$. Even though this is not a precise method to describe the overall quality of the air, we have chosen this approach in order to analyse the energy efficiency of the HVAC systems by correlating the ventilation rates with the $\mathrm{CO}_{2}$ levels. This way overventilation was avoided. Besides that, the measurement of $\mathrm{CO}_{2}$ concentration is much more cost efficient and easy to implement in practice, compared to solutions that involve a more thorough analysis of various other indoor pollutants (VOCs, PM, Radon, CO, $\mathrm{NO}_{2}$, Ozone etc.).

These being considered, for the present study the $\mathrm{CO}_{2}$ concentration and the relative humidity $(\mathrm{RH})$ have been used to characterize the general state of the IAQ. This approach is rather suitable for the case of a classroom where the main source of indoor pollution is represented by the persons inside and where the concentration of other pollutants is most probably lower due to the age of the building and due to the lack of interior decorations or excessive use of cleaning products (low VOC and formaldehyde emission).

The problem of particulate matter (PM) carried and/or generated by the high no. of students each day, and the apparition of mold due to inadequate humidity levels could still have an important impact on the IAQ. However, both pollutants are directly linked to the occupancy level, just like the $\mathrm{CO}_{2}$ emission. Therefore, any increase in $\mathrm{CO}_{2}$ levels means an increase in the ventilation rate demand, and a decrease in PM concentration and mold apparition rate (considering that the outdoor air does not present higher concentrations of PM, like the zones near parks). 


\section{Results and Discussion}

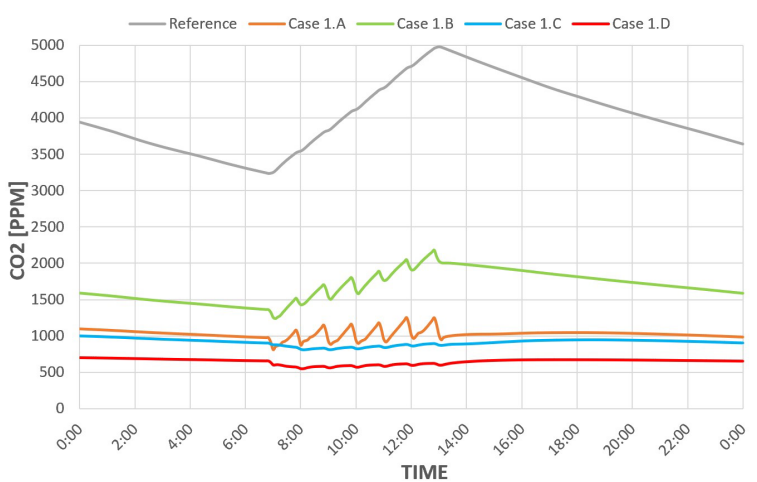

Fig. 3. $\mathrm{CO}_{2}$ Variation for Summer Specific Day (Tue $-4^{\text {th }}$ Jun)

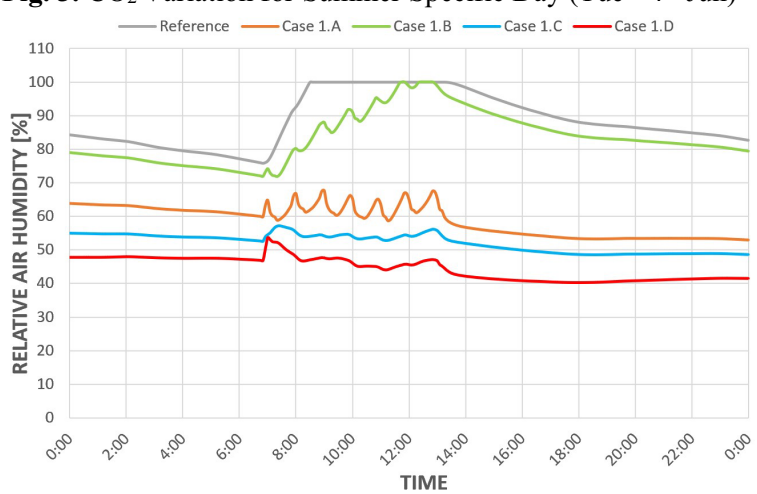

Fig. 4. Relative humidity Variation for Summer Specific Day (Tue - $4^{\text {th }}$ Jun)

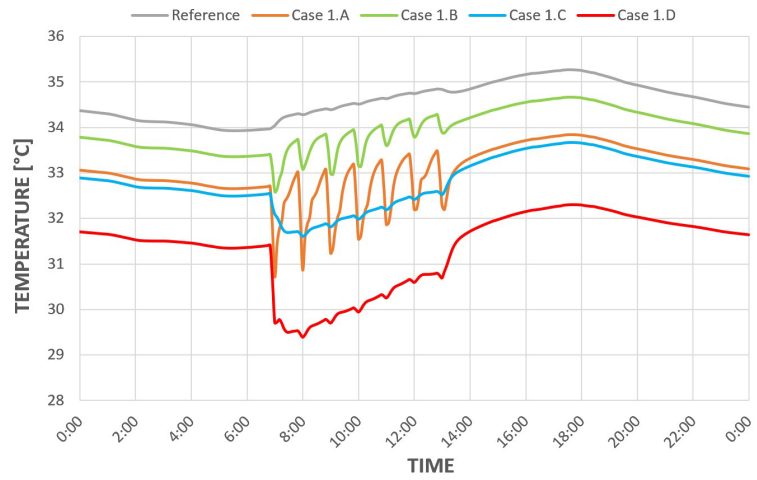

Fig. 5. Operative temperature Variation for Summer Specific Day (Tue $-4^{\text {th }}$ Jun)

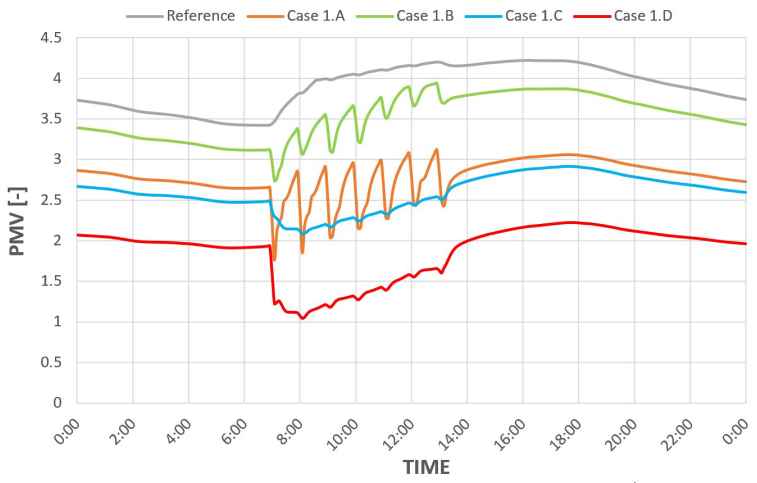

Fig. 6. PMV Variation for Summer Day (Tue $-4^{\text {th }}$ Jun)

During our study, more simulations have been run. These have included weekly simulations for summer and winter, daily simulations for representative summer and winter days, and yearly simulations. However, the results presented here are only for the summer specific day and winter specific day ( $4^{\text {th }}$ June and $22^{\text {nd }}$ January). These 2 dates have been manually chosen in order to have the same week day (Tuesday) and to represent the most unfavourable weather conditions during each season. The summer day was chosen in June because children are on vacation during the hotter summer months.

In Fig. 3, we can see that for the Reference Case, when all windows are closed (see Table 3), the $\mathrm{CO}_{2}$ levels start building up as soon as the students come into class. Considering that the windows stay closed during the whole week, the $\mathrm{CO}_{2}$ levels in a Tuesday morning are already at a very high level (3250 ppm) and they reach up to $5000 \mathrm{ppm}$, which is unacceptable for long exposure periods. It is worth mentioning that low Infiltrations have been considered for this case $(0-0.02 \mathrm{ACH})$, since the windows of the classroom are very well insulated.

A quick improvement can be noticed for Case 1.B and Case 1.A when one or all the windows are opened during class breaks. We can see that if only 1 window is opened, the $\mathrm{CO}_{2}$ still builds ups during the day, thus indicating that the ventilation rate $(1.2 \mathrm{ACH})$ isn't sufficient. However, the concentration is much lower (Min 1250 ppm/Max 2200ppm) than the Reference Case. Opening all 3 windows during breaks shows further improvement and no $\mathrm{CO}_{2}$ build-up during the day, which signifies that the ventilation rate $(3.6 \mathrm{ACH})$ is now enough (Min $810 \mathrm{ppm} / \mathrm{Max} 1250 \mathrm{ppm}$ ). Even so, there is still some $\mathrm{CO}_{2}$ build-up during classes. Keeping the windows opened at all time during the day (Case 1.C and Case 1.D) doesn't seem to improve the $\mathrm{CO}_{2}$ levels in a significant way, but the $\mathrm{CO}_{2}$ is no longer accumulating during classes. The overall values are close to the ones from Case 1.A.

Similar results can be noticed for the RH levels in Fig. 4, where the Reference Case and Case 1.B show very high humidity values $(70-100 \%)$. These are constantly out of the recommended $30-70 \%$ range for comfortable and healthy indoor air parameters. However, Case 1.A, 1.C and 1.D are all within the recommended values.

In terms of thermal comfort, in Fig. 5 and Fig. 6 it can be noticed that the Reference Case does show a very uncomfortable indoor environment, with pretty high temperature values. We can also notice that the insufficient ventilation rate for Case 1.B doesn't significantly improve the thermal conditions over the Reference Case. However, opening all 3 windows (Case 1.A) does provide a somewhat more comfortable environment. Still, during class, the temperature raises once again. It's interesting to see how Case 1.A and Case 1.C are very comparable, with the latter offering more consistent values during the day and no heat accumulation during classes. Finally, Case 1.D now shows a significant improvement in both temperature and PMV, but this amount of ventilation rate might also create local discomfort due to draught effect. 


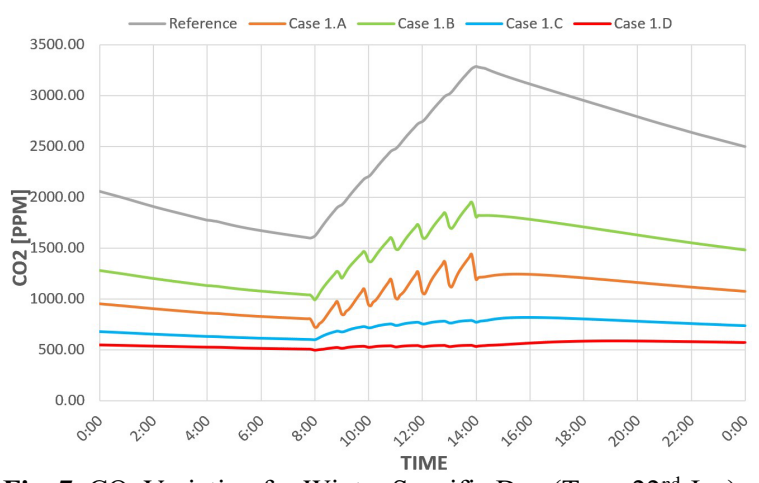

Fig. 7. $\mathrm{CO}_{2}$ Variation for Winter Specific Day (Tue $-22^{\text {nd }}$ Jan)

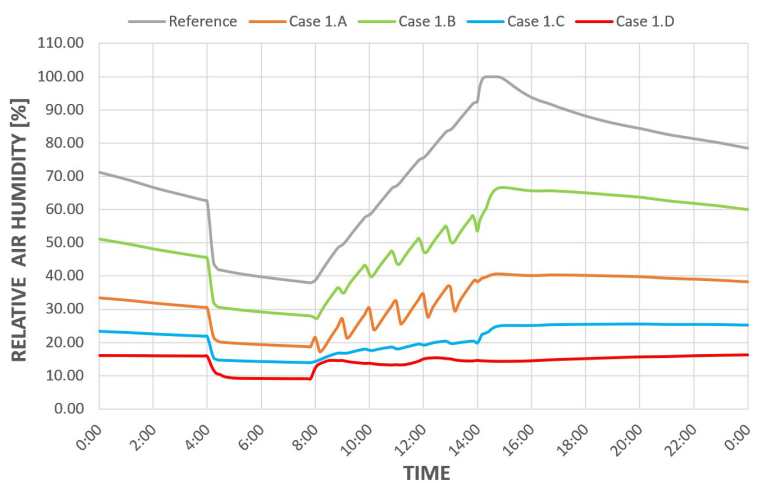

Fig. 8. Relative humidity variation for Winter Specific Day (Tue $-22^{\text {nd }}$ Jan)

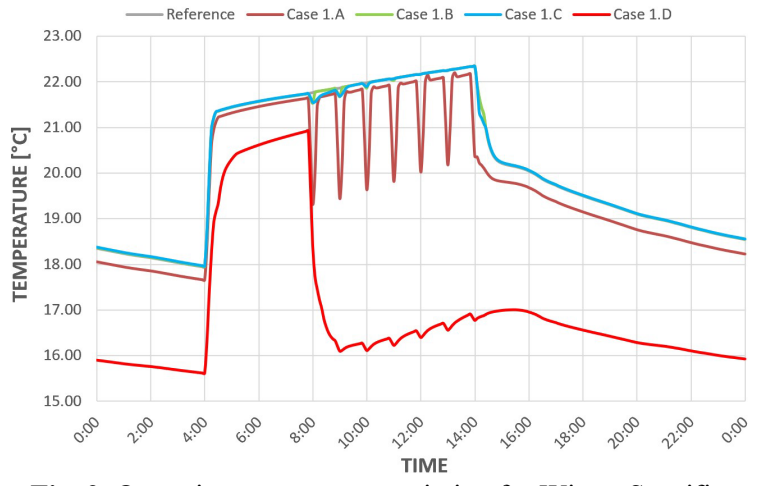

Fig. 9. Operative temperature variation for Winter Specific Day (Tue $-22^{\text {nd }}$ Jan)

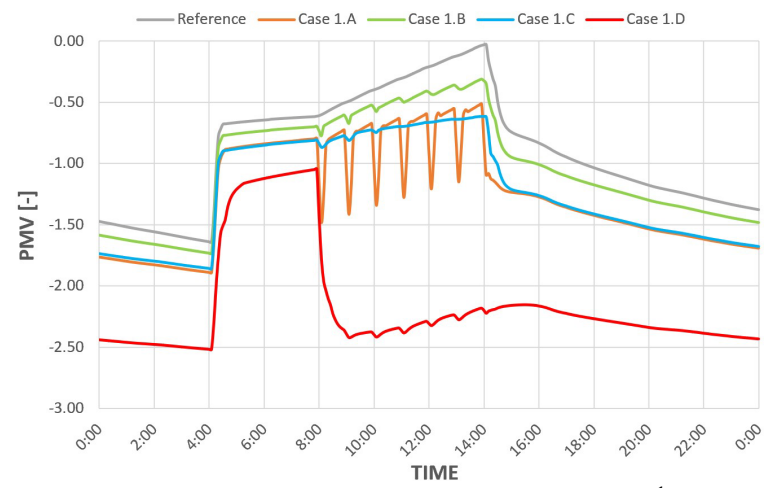

Fig. 10. PMV Variation for Winter Day (Tue $-22^{\text {nd }} J a n$ )

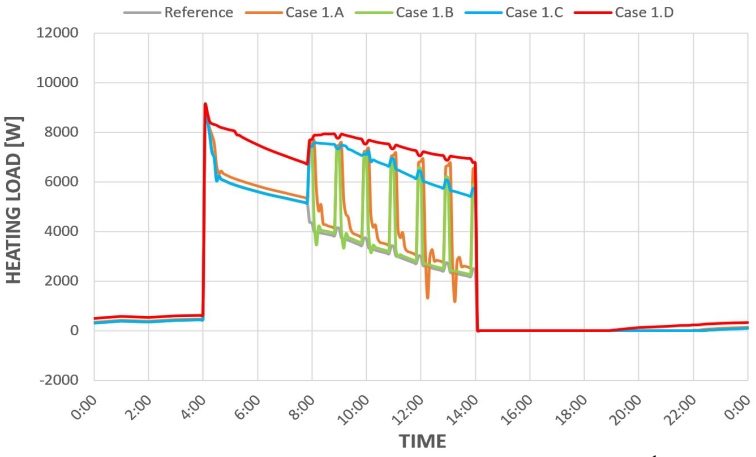

Fig. 11. Heating demand for Winter Day (Tue $-22^{\text {nd }}$ Jan)

For the winter specific day, the results for $\mathrm{CO}_{2}$ variation (Fig. 7) are like the summer case, but with overall lower concentration values for some reason. The only exception being for Case 1.A, where the $\mathrm{Max} \mathrm{CO}_{2}$ reaches $1450 \mathrm{ppm}$ vs $1250 \mathrm{ppm}$ for summer.

An interesting turn out is presented in Fig. 8, where the most suitable RH values are presented by Case 1.B, while the Reference Case still reaches very high values towards the end of the day. However, Case 1.A is now at the lower limit and Cases 1.C and 1.D are always under the minimum recommended values.

Obviously, the cold winter days that we usually encounter in Bucharest, are not very suitable for a natural ventilation system. Therefore, the thermal comfort results presented in Fig. 9 and 10 play an important role. This time, it can be noticed that the most comfortable conditions are given by the Reference Case. Then again, the high $\mathrm{CO}_{2}$ and $\mathrm{RH}$ levels don't make for a good indoor environment. Unfortunately, this is what happens in most schools during winter.

However, Cases 1.B and 1.C present very close values to the Reference Case, in terms of operative temperature. In both cases the temperature values during class are constantly between $20^{\circ} \mathrm{C}$ and $22.5^{\circ} \mathrm{C}$. This signifies that the heating system, the ventilation rates and the heating loads are well corelated to provide an adequate indoor environment. This can't be said for Case 1.A where a clear sudden drop in temperature can be seen during class breaks. This shows that the heating system can't keep up with the heat loss from the higher ventilation rate. Case 1.D should be avoided at all cost, since the heating system can't keep up and the temperature drop is too big. As a result, the thermal comfort drops to the lower end of the spectrum. It should be noted that the for the PMV a Clo level of 1 has been considered.

Another interesting factor to take into consideration during winter is the heat load (heating demand), in order to correlate the effectiveness of the ventilation with the heating capacity of the HVAC system. As seen in Fig. 11 , the heat load for most cases goes as high as $9000 \mathrm{~W}$. However, the total heating output during classes is around $8000 \mathrm{~W}$ (occupants + HVAC system). For Cases 1.B and 1.C this is enough to maintain a good indoor temperature. However, for Cases 1.B and 1.D we can notice the sudden temperature drops which reflect the insufficient heating output. 


\section{Conclusions}

This study was aimed at showing the impact of natural ventilation on the air quality inside a high school classroom for a typical summer and winter day. $\mathrm{CO}_{2}$ levels, air relative humidity, operative temperature and PMV were used as indoor air quality and thermal comfort indicators. Five different natural ventilation strategies have been tested using a numerical simulation software. Results have shown that keeping the windows closed increase $\mathrm{CO}_{2}$ and humidity accumulation during class hours. During summer days, heat build-up is also a concerning factor due to the high occupancy density. Opening 1 window during breaks didn't show significant improvement of either parameter as the $\mathrm{CO} 2$ level is rapidly accumulated during class time. This inefficient solution is nowadays the most used in existing educational buildings. Keeping all 3 windows opened at all time showed the best overall result. Therefore, keeping only 1 window opened might be the best and easiest solution for summer. During winter, keeping all windows closed can create an inadequate indoor environment. Results have shown that opening 1 window during breaks or during the entire day can significantly reduce $\mathrm{CO}_{2}$ and humidity accumulation while maintaining a good indoor temperature, however this solution may create in certain periods air draught in that area. Natural ventilation may be a solution, but the energy consumption is increased, and the need of a heat recovery ventilation is a better alternative.

\section{References}

1. A.M. Papadopoulos, Energy cost and its impact on regulating the buildings' energy behaviour Laboratory of Heat Transfer and Environmental Engineering Department of Mechanical Engineers Aristotle University Thessaloniki, Thessaloniki, Greece, (n.d.).

2. C. Ramos, Exposure to Air Air Exposure to Pollutants Pollutants During Physical Physical Activity, Instituto Superior de Educação e Ciências, 2016.

3. M. Wolfson, Defining Healthy Housing: The Competing Priorities of Energy and Indoor Air Quality in the Early 1980s, (2013) 1-17.

4. World Health Organisation, Evolution of WHO air quality guidelines, 2017.

5. I. Air, B. Munksgaard, I.A.I.R. Issn, Indoor air quality, ventilation and health symptoms in schools: an analysis of existing information, Indoor Air. (2003) 53-64.

6. S. Kephalopoulos, E. Csobod, Y. Bruinen de Bruin, E. de Oliveira Fernandes, P. Carrer, C. Cor Mandin, M. Stranger, I. Annesi-Maesano, M. Giacomini, E. Koudijs, [...], H. Kazmarová, M. Jajcaj, H.S. Vasiliki Assimakopoulos, M.N. John Bartzis Assimakopoulos, E.S. Gurzau, K. Kalimeri, I. Neamtiu, P. Van den Hazel, S. Montefort, A. Hadjipanayis, E. Cani, Technical Report: Guidelines for healthy environments within European schools, 2014. doi:10.2788/89936.

7. S. Gaihre, S. Semple, J. Miller, S. Fielding, S. Turner, Classroom carbon dioxide concentration, school attendance, and educational attainment, J. Sch. Health. 84 (2014) 569-574. doi:10.1111/josh.12183.

8. M.J. Mendell, G.A. Heath, Do indoor pollutants and thermal conditions in schools influence student performance? A critical review of the literature, Indoor Air. 15 (2005) 27-52. doi:10.1111/j.16000668.2004.00320.x.

9. O. Seppanen, W. Fisk, M.J. Mendell, Association of Ventilation Rates and CO 2 Concentrations with Health and Other Responses, Indoor Air. 9 (1999) 226-252.

10. J. Watt, J. Tidblad, R. Hamilton, V. Kucera, The effects of air pollution on the health of children, Paediatr Child Heal. 11 (2006) 513-516. doi:10.1007/978-0-387-84893-8.

11. W.J. Gauderman, E. Avol, F. Gilliland, H. Vora, D. Thomas, K. Berhane, R. McConnell, N. Kuenzli, F. Lurmann, E. Rappaport, H. Margolis, D. Bates, J. Peters, The Effect of Air Pollution on Lung Development from 10 to 18 Years of Age, N. Engl. J. Med. $351 \quad$ (2004) 1057-1067. doi:10.1056/NEJMoa040610.

12. W.N. Schofield, Predicting basal metabolic rate, new standards and review of previous work, 1985.

13. WHO, WHO | Human energy requirements, World Health Organization, 2004.

14. S. Haddad, P. Osmond, S. King, S. Heidari, Developing assumptions of metabolic rate estimation for primary school children in the calculation of the Fanger PMV model, Proceeding 8th Winsor Conf. Count. Cost Comf. a Chang. World. 8996 (2014) 10-13.

15. A. Persily, L. de Jonge, Carbon dioxide generation rates for building occupants, Indoor Air. 27 (2017) 868-879. doi:10.1111/ina.12383.

16. Design Builder, Design Builder - Air Temperature Distribution, Des. Build. Help. (2017).

17. S.J. Emmerich, A.K. Persily, State-of-the-Art Review of $\mathrm{CO} 2$ Demand Controlled Ventilation Technology and Application, 2001.

18. P. Wargocki, N.A.F. Da Silva, Use of visual CO2 feedback as a retrofit solution for improving classroom air quality, Indoor Air. 25 (2015) 105114. doi:10.1111/ina.12119.

19. G.A. Chamberlin, D.B. Myers, J.M. Jones, P. Rojeski, H. Singh, Carbon Dioxide and Ventilation Rates, Champaign, Illinois, 1995.

20. ASTM International, Standard Guide for Using Indoor Carbon Dioxide Concentrations to Evaluate Indoor Air Quality and Ventilation, in: ASTM D6245 - 07 Stand. Guid. Using Indoor Carbon Dioxide Conc. to Eval. Indoor Air Qual. Vent., 2007: p. 10. doi:10.1520/D6245-07.2. 